\title{
Management of Anteriorly Located C1-C2 Neurofibromata
}

\author{
Michael N. Bucci, M.D., John E. McGillicuddy, M.D., James A. Taren, M.D., \\ and Julian T. Hoff, M.D. \\ Section of Neurosurgery, University of Michigan Hospitals, Ann Arbor, Michigan
}

Bucci MN, McGillicuddy JE, Taren JA, Hoff JT. Management of anteriorly located C1-C2 neurofibromata. Surg Neurol 1990;

$33: 15-8$.

The authors discuss their recent experience with anteriorly located C1-C2 neurofibromata in five patients with cervical myelopathy and magnetic resonance scans consistent with intradural extramedullary masses in this region. Surgery was performed using a posterolateral approach with microscopic intradural exploration. Gross total intradural tumor removal was achieved in all cases. Improvement in cervical myelopathy occurred in all patients.

This report concludes that $\mathrm{C} 1-\mathrm{C} 2$ neurofibromata located anterior to the spinal cord can be totally and safely removed using a posterolateral approach. Improvement in neurologic dysfunction accompanies posterior decompression and gross total intradural tumor removal.

KEY WORDS: Cervical spine; Myelopathy; Neurofibromatosis

The diagnosis and management of neoplasms of the foramen magnum and upper cervical spinal cord have intrigued neurosurgeons for years. Frequently, these lesions resemble degenerative diseases of the central nervous system, resulting in diagnostic delay $[3,4,6]$. Surgical resection usually effects a cure, however, the optimal surgical approach to this region remains controversial $[2,5,9,10,16]$.

Recent advances in neuroradiologic imaging allow for improved visualization of central nervous system abnormalities, thereby facilitating the rapid diagnosis of neoplasms in the region of the foramen magnum and upper cervical spine $[1,13,14]$.

This report discusses the authors' recent experience with the diagnosis and management of anteriorly located C1-C2 neurofibromata.

\footnotetext{
Address Reprint Requests to: Michael N. Bucci, M.D., University of Michigan Hospitals, Section of Neurosurgery, 1500 East Medical Center Drive, Ann Arbor, Michigan 48109-0338.

Received May 19, 1989; accepted September 1, 1989.
}

\section{Material and Methods}

Between 1984 and 1988, eight parients presented to the University of Michigan Hospitals with high cervical myelopathy and myelographic evidence for $\mathrm{C} 1-\mathrm{C} 2$ neurofibromata. Seven of these eight patients had neurofibromatosis. The most common symptoms included weakness, spasticity, and incoordination. Preoperative magnetic resonance (MR) scanning demonstrated anteriorly located intradural, extramedullary masses at the C1-C2 level in five of the eight cases (Figure 1).

Table 1 illustrates the clinical profile of these five patients. There were two women and three men and the average age was 41 years. All patients were ambulatory upon presentation. Patient GA was the only patient who did not have neurofibromatosis.

Surgcry was performed with the patients placed in the prone position. A posterior midline incision was used and a wide C1-C2 laminectomy was performed. Additional lateral bony decompression was performed to the lateralizing side of the tumor, if present. All patients had extradural tumor as well; however, the intradural portion was removed first.

Upon opening the dura, the operating table was rotated $15^{\circ}$ to $30^{\circ}$ to facilitate exposure (Figure 2). Sectioning of the dentate ligaments and at times the posterior cervical nerve roots provided increased access to the tumor and increased mobility of the cervical spinal cord. The ultrasonic surgical aspirator was used to resect tumor in all cases (Figure 3).

In cases of gross total extradural tumor removal, the dural attachment was resected and a patch graft placed. Otherwise, the dural attachment was cauterized and repaired primarily.

\section{Results}

Gross total intradural tumor removal was achieved in all five patients. Pathological diagnosis was benign neurofibroma in all cases. Gross total extradural tumor removal was possible in three of five cases. One patient (FS) developed a spinal accessory nerve palsy which partially resolved. There were no cases of swan-neck deformity 


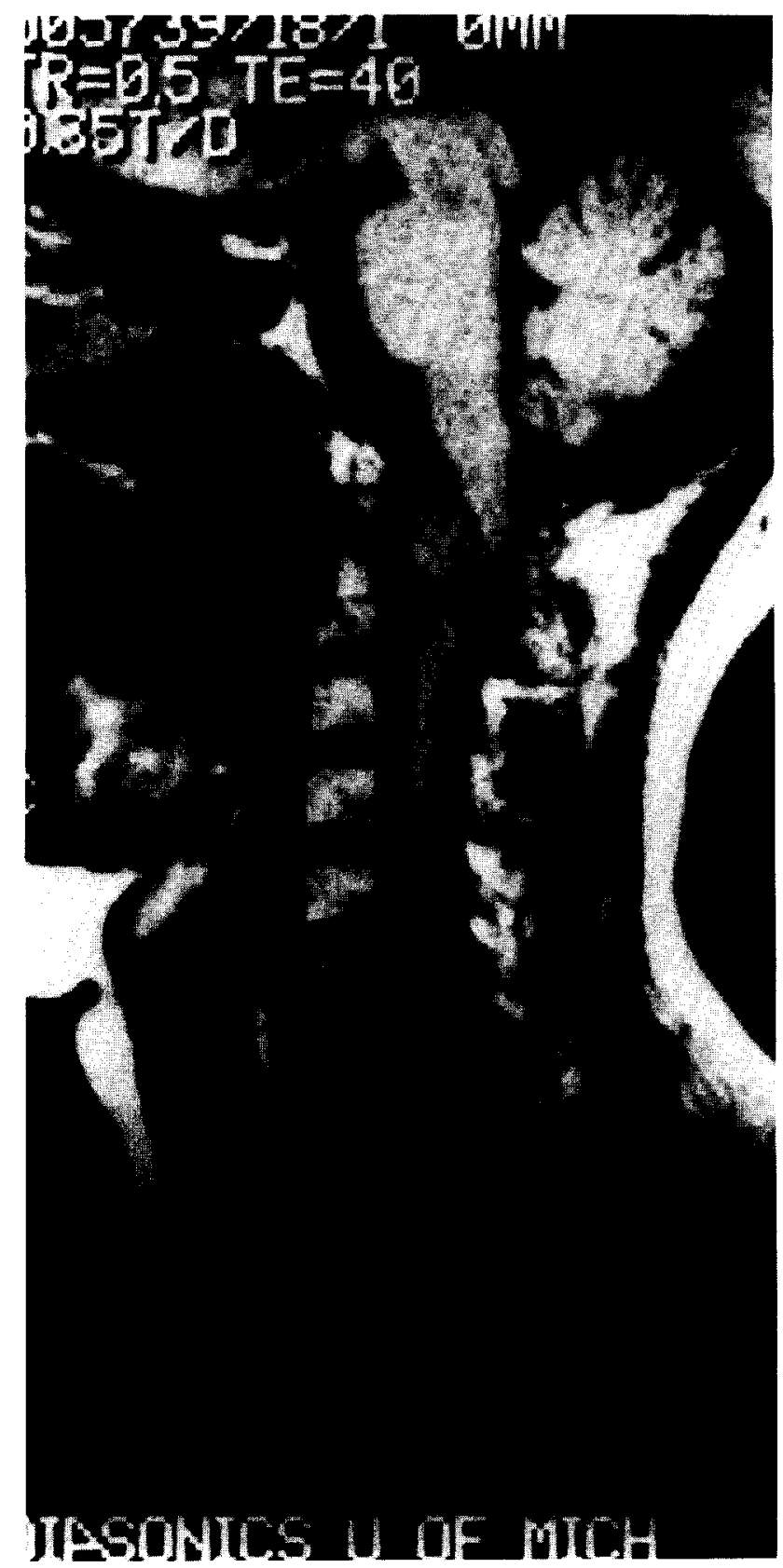

Figure 1. Sagittal MR scan of patient $G A$ demonstrating a mass located anterior to the spinal cord at $C 1-C 2$, with resultant anteroposterior compression.

noted on postoperative $\mathrm{x}$-rays. Improvement in myelopathy occurred in all five patients.

\section{Discussion}

One of the first reports regarding surgical management of upper cervical spinal cord tumors was by Elsberg in 1929 [4]. He described rotating the spinal cord on a divided slip of the dentate ligament to resect ventrally located tumor.

The Mayo Clinic has reported the largest series of patients, which has been divided into three consecutive reports. In 1956, Dodge et al [3] reported 30 benign tumors diagnosed between 1924 and 1956; 26 were meningiomas and 4 were neurofibromas. Yasuoka et al [16] reported the next series of 57 patients diagnosed between 1957 and 1976. This was followed by the comprehensive review of the Mayo Clinic experience of 102 total cases between 1924 and 1982 by Meyer et al [9]. There were 78 meningiomas, 23 neurofibromas, and 1 teratoma. The most frequent complaints were neck pain, ataxia, numbness, and incoordination. All patients were operated on in the sitting position using a posterior approach. Myelography and computed tomography were used when available.

Howe and Taren [6] described the pitfalls in diagnosing these lesions in six patients. They felt that a uniform clinical syndrome did not exist to describe the clinical manifestations of these tumors. Factors that were suggestive included cervical pain, upper motor neuron signs, and mixed sensory deficits.

Recently, Wagle et al [14] described the value of MR scanning in the diagnosis and management of four cases of foramen magnum meningioma. Prior to MR scanning, the radiological diagnosis of foramen magnum lesions was best imaged by myelography $[7,8]$.

The incidence of central nervous system neurofibromata is increased in neurofibromatosis [11]. These lesions rarely undergo malignant degeneration [12]. The increased association between spinal column abnormalities and neurofibromatosis has been previously described $[15,17]$.

In this report, seven of the initial eight patients had neurofibromatosis $(88 \%)$, while in the comprehensive Mayo Clinic review, less than $50 \%$ of their patients with C1-C2 neurofibromas had neurofibromatosis [9]. Although these lesions are frequently difficult to diagnose, the increased incidence of neurofibromatosis in this re-

Table 1. Clinical Profile of Five Patients with Anteriorly Located C1-C2 Neurofibromata

\begin{tabular}{|c|c|c|c|}
\hline & Age/Sex & Signs and symptoms & Year \\
\hline MB & $24 \mathrm{~F}$ & $\begin{array}{l}\text { Right-sided weakness, } \\
\text { incoordination }\end{array}$ & 1984 \\
\hline $\mathrm{GA}$ & $45 \mathrm{~F}$ & $\begin{array}{l}\text { Upper extremity } \\
\text { weakness, spasticity }\end{array}$ & 1986 \\
\hline MG & $44 \mathrm{M}$ & Incoordination, spasticity & 1987 \\
\hline FS & $67 \mathrm{M}$ & $\begin{array}{l}\text { Weakness, ataxia, } \\
\text { spasticity }\end{array}$ & 1988 \\
\hline RE & $25 \mathrm{M}$ & $\begin{array}{l}\text { Upper extremity } \\
\text { weakness, lower } \\
\text { extremity spasticity }\end{array}$ & 1988 \\
\hline
\end{tabular}



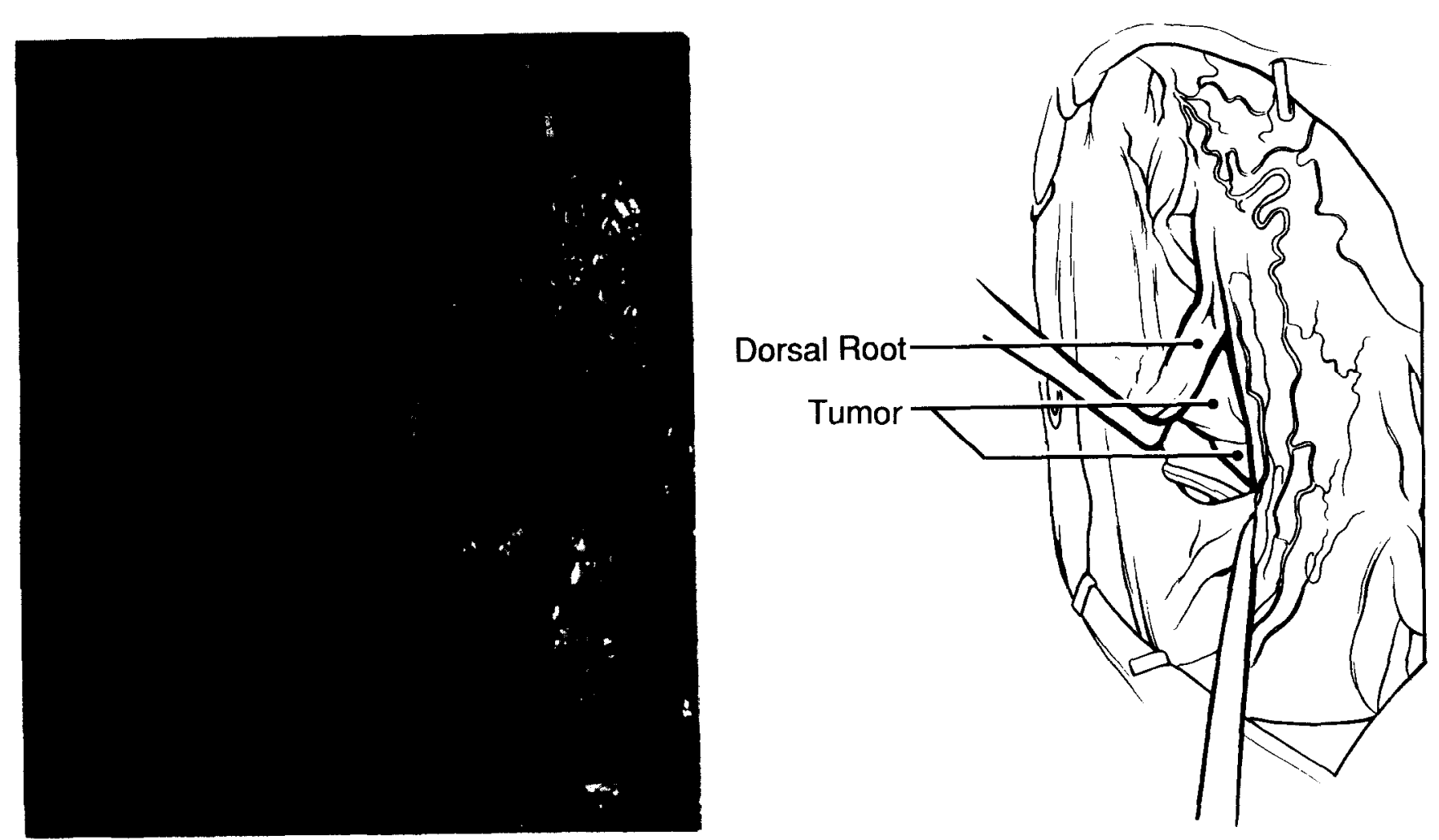

Figure 2. Intraoperative view and diagram of patient FS demonstrating posterior and lateral exposure of an anteriorly located C1-C2 neurofibroma.
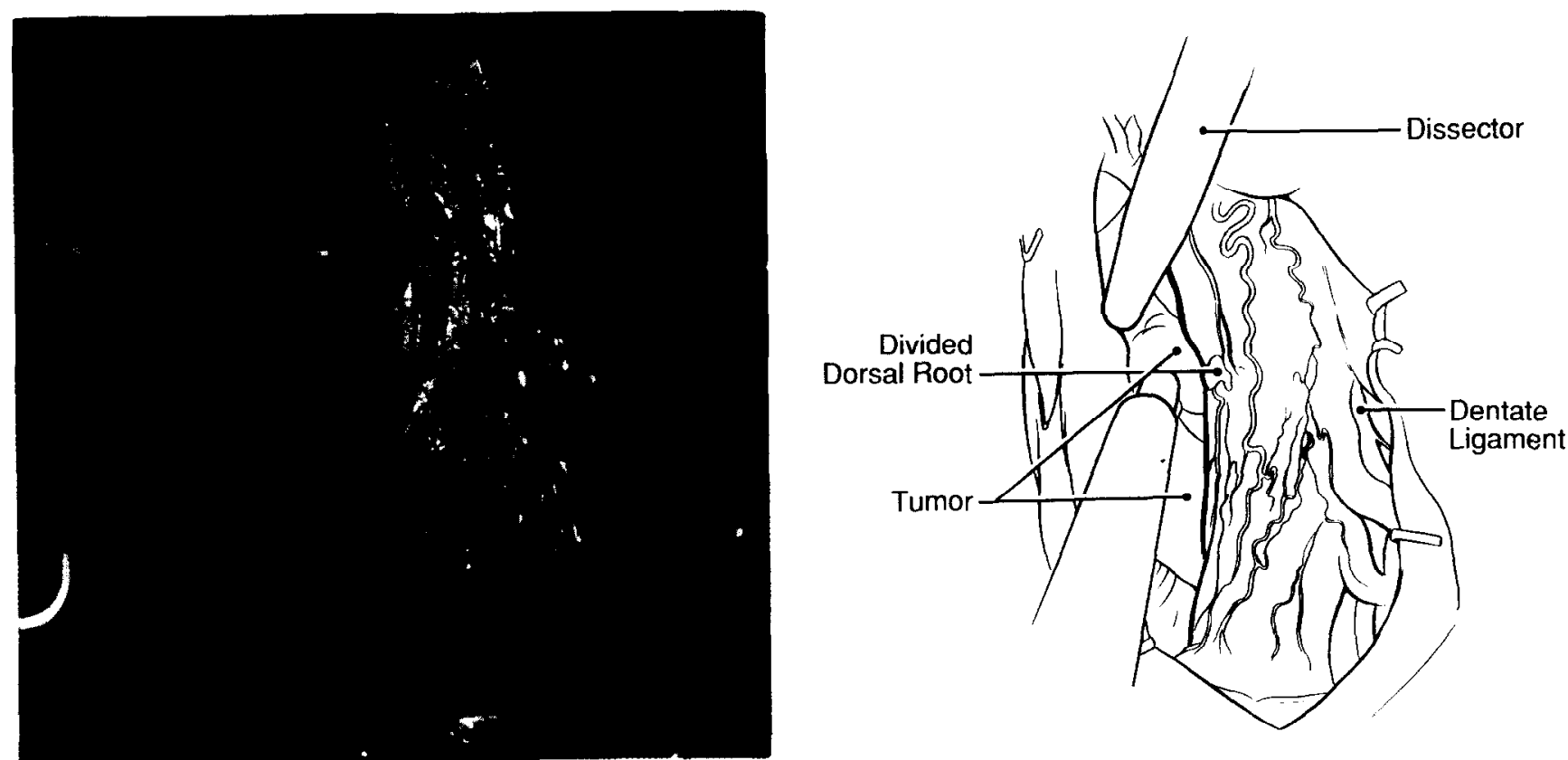

Figure 3. Intraoperative view and diagram of patient FS demonstrating sectioning of the dorsal roos of C2, gentle traction on the tumor, and ultrasonic surgical aspiration of the tumor. 
port resulted in early imaging with myelography and MR scanning, thereby facilitating diagnosis.

Gross total extradural tumor removal was possible in only three of five patients. In the remaining two patients, tumor was encasing the vertebral arteries bilaterally, thereby limiting total tumor removal. A thorough decompression was achieved in both patients, however.

Surgical resection of the anteriorly located tumor was facilitated through use of the ultrasonic surgical aspirator. Together with sectioning of the dentate ligaments, this instrument allowed for careful tumor debulking and removal in all five patients.

There were no postoperative spinal cord complications, and cervical myelopathy improved in all five patients. One patient developed a spinal accessory nerve palsy. This nerve was draped over tumor and presumably was injured due to manipulation. A more lateral exposure and approach may have avoided excessive manipulation, allowing for tumor debulking anterior to the nerve.

Despite the recent enthusiasm for anterior trans-oral approaches to this region of the spine and foramen magnum, this report demonstrates that certain anterior lesions can be safely approached and resected posteriorly [10].

Although MR scanning was invaluable in the initial work-up of this group of patients, it also proved useful in the follow-up management in three of five patients, including the patient who developed a spinal accessory nerve palsy.

This report concludes that (1) MR scanning is a sensitive and noninvasive means of imaging the upper cervical spine in patients with neurofibromatosis and cervical myelopathy, (2) C1-C2 neurofibromata located anterior to the spinal cord can be totally and safely removed using a posterolateral approach, and (3) improvement in neurologic dysfunction accompanies posterior decompression and gross total intradural tumor removal.

The authors thank Ms. Pat Frye for her assistance in the preparation of this manuscript.

\section{References}

1. Bale JF Jr, Bell WE, Dunn V, Affi AK, Menezes A. Magnetic resonance imaging of the spine in children. Arch neurol 1986;43:1253-6.

2. Cohen $L$, Macrage $D$. Tumors in the region of the foramen magnum. J Neurosurg 1962;19:462-9.

3. Dodge HW Jr, Love JG, Gotlieb CM. Benign tumors at the foramen magnum. Surgical considerations. J Neurosurg 1956;13:603-17.

4. Elsberg CA. Tumors of the spinal cord. Problems in their diagnosis and localization; procedures for their exposure and removal. Arch Neurol Psych 1929;22:949-65.

5. Guidetti B, Spallone A. Benign extramedullary tumors of the foramen magnum. Surg Neurol 1980;13:9-17.

6. Howe Jr, Taren JA. Foramen magnum tumors. Pitfalls in diagnosis. JAMA 1973;225:1061-6.

7. Malis LI. The myelographic examination of the foramen magnum. Radiology 1958;70:196-221.

8. Marc JA, Schechter MM. Radiological diagnosis of mass lesions within and adjacent to the foramen magnum. Radiology 1975;114:351-65.

9. Meyer FB, Ebersold MJ, Reese DF. Benign tumors of the foramen magnum. J Neurosurg 1984;61:136-42.

10. Mullan S, Naunton R, Hekmat-panah J, Vailati G. The use of an anterior approach to ventrally placed tumors in the foramen magnum and vertebral column. J Neurosurg 1966;24:536-43.

11. Riccardi VM. Von Recklinghausen neurofibromatosis. New Engl J Med 1981;305:1617-27.

12. Sands MJ, McDonough MT, Cohen AM, Rutenberg HL, Eisner $J W$. Fatal malignant degeneration in multiple neurofibromatosis. JAMA 1975;233:1381-2.

13. Schroth G, Thron A, Guhl L, Voigt K, Niendorf H-P, Garces LR-N. Magnetic resonance imaging of spinal meningiomas and neurinomas. Improvement of imaging by paramagnetic contrast enhancement. J Neurosurg 1987;66:695-700.

14. Wagle VG, Villemure JG, Melanson D, Ethier R, Bertrand G, Feindel W. Diagnostic potential of magnetic resonance in cases of foramen magnum meningiomas. Neurosurgery 1987;21:622-6.

15. Winter RB, Moe JH, Bradford DS, Lonstein JE, Pedras CV, Weber AH. Spine deformity in neurofibromatosis. J Bone Joint Surg (AM) 1979;61:677-94.

16. Yasuoka S, Okazaki H, Daube JR, MacCarty CS. Foramen magnum tumors. Analysis of 57 cascs of benign extramedullary tumors. J. Neurosurg 1978;49:828-38.

17. Yong-Hingk, Kalamchi A, MacEwen GD. Cervical spine abnormalities in neurofibromatosis. J Bone Joint Surg (AM) $1979 ; 61: 695-9$. 